\title{
Counseling Intern Self-Efficacy and The Big Claw Metaphorical Activity: A Qualitative Empirical Study
}

\author{
Michael Maxwell* \\ Counseling and Higher Education, USA
}

*Corresponding author: Michael Maxwell, Clinical Assistant Professor, Counseling and Higher Education, USA.

Received Date: September 25, 2019

Published Date: November 08, 2019

\section{Abstract}

The purpose of the current qualitative study was to demonstrate the efficacy of an innovative instructional strategy for assessing self-efficacy of counselors-in-training. The results of the study provide the themes that emerged from the collected data. The assignment and script offer an innovative way for counselor educators to assess their counseling intern students' levels of self-efficacy by use of the Big Claw Metaphorical Activity. It was concluded that this activity may assist counselor educators in helping to develop counseling interns' levels of self-efficacy when working with clients in counseling.

Keywords: Counselor; Intern; Self-Efficacy; Qualitative; Instruction

\section{Introduction}

As a counselor educator for a graduate program, the author recognized a wide variety of student experiences, skill sets, and performance confidence levels. The common curriculum sequence for graduate counseling students is to complete (or near complete) their didactic coursework and pre-practicum interactions prior to entering their internship clinical experience at a mental health agency. Having successfully completed the coursework and skill practice experiences, in theory, counseling students have exhibited the readiness to transition from a solely classroom-style learning to utilizing their learned skills with their clients at their internship agencies.

Functioning as a practicum and internship seminar instructor, the author also observed a variation of student confidence levels for working with actual clients at a mental health agency, despite the preparation that took place prior. In order to meet the individual needs of each intern student while working in a group seminar format, the author recognized the need to first assess the current level of self-efficacy for each student. The purpose of this study was to demonstrate the effectiveness of an innovative instructional strategy for assessing self-efficacy of counselors-in-training. The research question that encouraged the purpose was the following: what common themes might emerge from conducting a qualitative inquiry into a directed activity for counseling students' experiences, potentially shedding light on the participants' self-efficacy in the work of counseling?

\section{Self-efficacy}

How one psychologically approaches a given task is directly associated with how he or she views how he or she will perform in that task [1]. Counseling students tend to vary in their personal and professional experiences, which can bare a substantial impact on how they feel about their ability to work with others in a counseling setting.

According to Al-Darmaki [2], counselor educators have observed that some students experience anxiety and self-doubt at the beginning of their practicum classes, potentially as a result of low self-efficacy. The potential problem for counselor educators is having a reliable tool for assessing practicum and intern students' levels of self-efficacy. Counselor educators' ability to accurately assess the level of self-efficacy of their practicum and intern students is imperative for gauging where to modify the training curriculum.

This idea of personal ability (sense of worth) as related to certain tasks can be viewed as self-efficacy. Self-efficacy stems 
from the seminal work of Albert Bandura and his Social Cognitive Theory, where human behavior is defined as an interaction of personal factors, behavior, and the environment [3-5]. Selfefficacy was defined by Bandura [2] as "the conviction that one can successfully execute desired behavior" (p. 93). Bandura [5] expanded his definition of self-efficacy "as people's beliefs about their capabilities to produce designed levels of performance that exercise influence over events that affect their lives".

Furthermore, self-efficacy is considered an individual's confidence that he or she can successfully accomplish a given task. Bandura's [3] research indicated that individuals who possessed high levels of self-confidence in their own abilities would approach difficult tasks as challenges rather than as obstacles and approach threatening situations with assurance that they can exercise control over the situation. Additionally, other social cognitive constructs, such as counselor anxiety and outcome expectations, may be important facilitators in the relationship between counselor selfefficacy and counselor performance [6]. According to Larson and Daniels [7] counseling self-efficacy (CSE) is defined as "one's beliefs or judgments about his or her capabilities to effectively counsel a client in the near future".

Implicit assumptions of counseling self-efficacy theory include the following:

- $\quad$ CSE is a primary mechanism through which effective counseling occurs and strong CSE beliefs result in enhanced counselor-in-training perseverance in the face of difficult counselor tasks;

- counseling students who experienced higher levels of counseling self-efficacy are better able to receive and incorporate evaluative feedback into their learning experiences than students who do not have high counseling self-efficacy [79].

One of the major goals of counselor supervision and training is to develop proficient counselors by increasing their level of competency and self-efficacy [8] [10-12]. If counselor educators and supervisors can identify specific variables that influence the outcome of supervision, they may then be able to tailor their instruction to best fit the individual needs of each counseling student.

According to Fernando and Hulse-Kilacky [13], a relationship exists between having a sense of preparedness and the perceived self-efficacy of counselors-in-training regarding their ability to handle crisis interventions. Self-efficacy may be a critical variable in the perceived sense of preparedness experienced by beginning counselors faced with crisis situations. Ambiguity is commonly accepted as an inherent characteristic in counseling. While experienced practitioners may be better capable of working with ambiguous therapeutic content, some ambiguous tasks can have the tendency to generate a sense of crisis in beginning counseling students.

\section{Ambiguity}

Sawyer, Peters, and Willis [1], defined ambiguity, or the state of being ambiguous, as being open to more than one interpretation or being uncertain. Ambiguity tolerance is congruent with human development, thus a necessary component of counseling student development, identity, and effectiveness. The goal for counselor educators is to create effective counselors in addition to promoting the optimal counselor identity development of the counselors-intraining. Anxiety and frustration are expected when students are faced with increasingly ambiguous concepts of counseling [1,14]. Accepting ambiguity's place in the counseling relationship, and how to respond to it can be an important element to any counseling training program.

Self-efficacy and trust in the counseling process are essential elements in addressing this concern of ambiguity [15]. The more important question becomes, what is the role of ambiguity in fostering counselor identity development and enhancing counseling effectiveness. Validating the role of ambiguity may be a helpful way of making meaning of the struggles and frustrations many counseling students experience in their training $[14,16]$ Effective counselor educators can connect educational experiences to the unavoidable interactions and emotions encountered by counseling students (i.e., ambiguity). Perhaps counselor educators may assume responsibility for recognizing that ambiguity does exist as a legitimate part of the counseling student's learning processes. Ambiguity can be expected as an element inherent in the counseling process. This innate characteristic is not necessarily one to attempt to reduce, but instead, mitigate its undesirable impact. Reflective of the current study, counselor educators may help students to reframe their understanding of their core skills by addressing their purpose. An operative connector for assisting counseling students with comprehending ambiguity's function in the counseling process is the use of metaphor. According to Kaufer [17], it is difficult to conceptualize ambiguity without its tie to metaphorical ideology.

\section{Metaphor}

According to the Merriam-Webster [18] definition, a metaphor is a figure of speech in which a word or phrase literally denoting one kind of object or idea is used in place of another to suggest a likeness or analogy between them. In other words, a metaphor can be considered a phrase or idea used to compare two originally unlike thoughts, but typically have a single common characteristic. Metaphors are used to help create a clearer, more relevant description from the metaphorical content to the actual concept.

In a fundamental way of thinking, metaphors are any activity that communicates to the self (Lankton \& Lankton, 1989). Fox [19] expanded this notion by considering metaphors to assist in the organization of personal experiences. According to Powell and Royce [20] metaphors can be considered an alternate way of knowing in contrast to rational and empirical knowing. Metaphors allow students the avenue for considering alternative possibilities 
to modify their self-conceptual paradigm [21,22]. Therefore, metaphors can be used as a source of meaning making, thereby becoming a useful tool in counseling and counselor education.

Awareness of preconceived beliefs about self, constitutes an important step in the change process. Metaphors do not change an actual issue, but instead, the student's perception of the issue [23]. With this said, we use metaphors to understand our experiences from a novel perspective. Metaphors are fundamental in the way we think [24].

\section{The Use of Metaphor in Counselor Training}

Counseling students have theories about themselves that directly influence their practice. It is important for students to clarify these self-theories, and metaphors are effective ways to ascertain these personal assumptions [25,26].

Oftentimes, when we are unable to find the language to express our thoughts, we resort to metaphors to assist in creating that clarity. Metaphors not only have the power to describe self but can also transform self. According to Leary [27], these metaphorical concepts are not simply descriptive, they have also been transformative: "their use has led to changes in human self-reference and hence to human self-consciousness" (p. 14). According to Langer [28], a specific reason for the broad appeal of metaphor as a means of eliciting growth and change is that it allows new knowledge and ideas to be conveyed using frames of reference that are familiar to the learner.

A possible life-occurrence may alter a counseling student's view of self. For example, despite learning adequate skills and receiving quality supervision, a counselor in training might experience unexplained client loss. A counselor in training might also experience a client's suicide, anger at the counseling process or perceived idea that the counselor is nothelpful. These situations may affect counseling student self-efficacy [29]. Taking this concept one step further, Leary stated the following: "How counselors perceive the organization of the self, and the metaphors they use, is reflected in the approaches they take when engaging with clients" (p. 243). Furthermore, it is difficult to adequately prepare a counselor in training for these types of situations. One possible method to help counselors in training become aware of these realities and accept that clients may not respond to counseling efforts is introducing an experiential, metaphorical exercise [30].

Sommer and Jane [31] discovered that using metaphorical activities to enhance supervision is to facilitate personal interpretations that can help the counselor-in-training and supervisor understand and give meaning to the phenomenological experience of being new counselors. The use of myths and stories as metaphors for counseling and supervision may provide rich opportunities for discussion and reflection for supervisors and counselors-in-training as beginning counselor develop competence, confidence, and a professional sense of self.

According to Campbell [32], metaphors also allow people to ascribe affect to language by evoking past emotions. Supervision is commonly conceptualized as a process that involves a progression through various developmental stages. Sometimes this process could be a painful and turbulent experience for the counselorin-training [32]. Hence, metaphor can be exercised as a tool for helping counselors-in-training understand this developmental process [30].

It is essential for counselors-in-training to become aware of the layers of their own defense systems, which have evolved from past evaluative experiences. The purpose of this process is to prevent the beginning counselors from

- Becoming overly defensive or

- $\quad$ Project their past supervision experiences on the current evaluative process.

Fall and Sutton (2004) presented an example of a structured metaphoric drawing activity in which the counselors-in- training were asked at the mid-semester point of their field observation to draw pictures that depict the students' perceptions of their stage of development in becoming a counselor.

Counseling students reported they believed the activity helped them identify issues within their experiences that were previously unrecognized, facilitating their ability to conceptualize these struggles and triumphs within the context of their own developmental process of becoming a counselor (Fall \& Sutton, 2004).

Giuffrida, Jordan, Saiz and Barnes, (2007) discovered that metaphoric activities can provide a valuable tool for facilitating counselors-in-training growth and development. Metaphoric activities seem to be particularly useful in helping counselorsin-training understand the process of becoming a counselor. The benefits associated with metaphoric activities include allowing supervisors and counselors-in-training to develop a shared language with which to conceptualize cases, help counselors-intraining think about their interactions with a client in a novel frame, and encouraging students to find their own solutions to problems rather than relying on their supervisors for answers [33].

\section{Method}

Considering the paucity of empirical research in the area of assessing counseling student self-efficacy, a phenomenological qualitative research method was chosen to collect, analyze, interpret, and report the data. It seemed most fitting to envision the current study from a phenomenological lens, as the participants' individual and personal perspectives will provide the substance of the emerging themes. According to Polkinghorne (1989), phenomenological psychology is a perspective that recognizes the domain of meaningful experience as the fundamental location of knowledge. Phenomenological psychology allows for the investigation of structures that are typical or general for groups of people. When using a phenomenological psychology method, the researcher places the emphasis on descriptions from the research participants instead of the researcher's self-report [34,35]. Giorgi 
(1985) stated that "by adopting a strictly descriptive approach, we can let the phenomena speak for themselves, and when we do, we discover that whatever appears suggests in its very appearance something more which does not appear".

According to Barnes (2004), qualitative methods are often more helpful than traditional quantitative measures for understanding counselor-in-training self-efficacy beliefs within the self-efficacy in context approach. Qualitative assessment involves exploration of a counseling student's past experiences with self-efficacy and its related constructs, such as evaluation anxiety or degree of identification with the counselor role. The author chose to use Creswell's (2009) method for collecting, analyzing, and interpreting qualitative data.

\section{Data Collection}

The data from the sample population for this study were collected over multiple academic semesters. Students enrolled in the Counseling Practicum course at a small University in the Southwest United States were given the assignment to engage in the big claw activity (assignment/script to follow later in this Method section). Participants were assured that their confidentiality would be maintained, and that no identifiable information would be used in the report.

\section{Data Analysis}

The six-step analysis and interpretation process outlined by Creswell (2009) was utilized to unveil the themes that emerged from the data. Creswell's (2009) six steps are as follows:

- $\quad$ categorize and plan the data for analysis,

- $\quad$ read though all the data,

- $\quad$ organize data by coding according to theme,

- generate descriptions of the setting, participants, and themes utilizing the code process,

- describe the findings in a qualitative context, and

- $\quad$ interpret the meaning of the analyzed data.

Organizing and preparing the data for analysis involved transcribing interview notes, visually scanning material, sorting, and arranging the data into different types of categories. In this first step, all the data was read to obtain a general sense of the information and to reflect on its overall meaning. The author reflected upon the general ideas of the participants, the tone of the ideas, and the impression of the overall depth, credibility, and use of the information.

The next step was to initiate a detailed analysis with a coding process that allowed the codes to emerge during this step. The coding process involved taking text data gathered during data collection, segmenting participant statements, and labeling those categories in vivo, literal terms. Creswell (2009) suggested, "during coding often a term based in the actual language of the participant is called in vivo". The author utilized coding to generate a small number of themes or categories that are presented in the results section of the study.

\section{Data Interpretation}

The final step in data analysis involved making an interpretation or meaning of the data. Researchers asking themselves what lessons were learned captures the essence of this step [36]. Creswell (2009) stated these lessons could be the researchers' personal interpretations, embedded in the understanding that the researcher brings to the study his or her own culture, history, and experiences. The interpretation of the meaning of the data suggested a variety of novel questions that needed to be asked. Such questions emerged from the analyzed data, not foreseen earlier in the study.

\section{Credibility and Trustworthiness}

Credibility was achieved by implementing the following techniques: triangulation, persistent observation (recording the individual interviews), thick descriptions (verbatim participant responses), and member checking. The author was able to utilize triangulation as a method for ensuring credibility using multiple sources, which allows the researcher to focus on a broader range of issues, but also provides converging lines of inquiry. The multiple sources utilized to support triangulation were in-depth interview questions and participant demographic information. In addition, the researcher maintained a reflexive journal throughout the data collection, analysis, and interpretation process. The reflexive journal proved helpful in bracketing the researcher's biases when any arose. Finally, during the data analysis stage, feedback from the participants was compared to determine areas of agreement as well as areas of discrepancy.

According to Creswell (2007), thoroughly describing the elements of a study allows the audience the capability to decide the transferability of the researcher's descriptions. A detailed description of each stage of the participant recruitment process, data collection process, data interpretation process, and data reporting are included in this study. To further ensure trustworthiness, the author included samples of the rich responses of the actual participants in the results section of my dissertation. Maxwell (1992) stated that using the participants' verbatim responses is a way of increasing interpretive validity.

\section{Participants}

Participants for this study were students from the Counseling Practicum courses that the author taught from 2012-2016. All participants were master's level counseling students who completed all didactic, classroom courses in their counselor education programs. There were 64 participants in this study, of whom, 56 participants were women and 8 were men. Their ages ranged from 24-66 years, with a mean age of 36.8. The racial identifications of the participants were 35 African American, 17 White, six Latino, two Muslim American, one Asian American, one Italian American, and one biracial. 


\section{Instrument}

When the author taught the practicum course for his counselor education program, he traditionally utilized the Big Claw Metaphor Activity script toward the end of the first-class meeting. He instructs the students to engage in the activity between the first-class meeting and next, upcoming class meeting. This activity would be appropriate at many junctures within the counseling student's education, for example in either of the early skills development courses, practicum courses, or internship courses.

Big claw metaphor script: Instruct the students to engage in the following out-of- classroom activity: Students, you are to find your local, neighborhood big claw machine. A big claw machine is a large toy apparatus that requires the player to insert either coins or tokens to play. A big claw machine is typically tall, rectangular in shape and translucent; much resembling a snack vending machine. After inserting the required payment, the player is then allowed to control a lever that will eventually drop a claw-shaped 'grabber'. The objective of the game is to successfully grab a content item inside the machine, direct the object toward the final door, and drop the item for the player's final possession. Each student is to have only five attempts at obtaining a 'prize' from their chosen big claw machine. If you can successfully grab a prize in less than 5 chances, then you may discontinue your attempts. If you are unable to grab a prize in the allotted 5 chances, then you must discontinue. Finally, be prepared to share the narrative of your experience when we have our next class meeting.

Processing the big claw metaphor experience: The author opened a forum for discussing the students' reaction during the next class period following the big claw homework activity. The following will show the experience processing prompts, while a variety of student responses will appear in the results section. The initial prompt the students are asked is the following: "please share your initial reaction to the homework assignment immediately after receiving your instructions." Next, the students were asked to respond to the following: "please share any thoughts (including any planning) you may have had between first receiving the assignment and actually engaging with the big claw machine.

" After allowing the students to respond, the following prompt was offered: "please share your thoughts and reactions while you were attempting to grab a prize from the big claw machine." The final question the students were asked was the following: "what thoughts and feelings did you experience between the time you completed your attempts with the big claw machine and coming to class today."

\section{Results}

The results of this study allowed the authors to explore the participants' feelings towards their own abilities to master a task with a clear objective, but uncertain end results. The author believes the big claw activity mimics the counseling process, in that there is a clear set of instructions for obtaining a prize (general counseling process), several strategies for grabbing the prize (chosen theoretical orientation), and a variety of occurrences follow (client and counselor reactions). The author examined all the participants' responses and clustered them into general thematic meaning. The author then broke out topics that appeared to contribute to a set number of premises. The author was able to identify several themes that emerged from the transcript data. As a result of this structured and detailed process, the following topics emerged: apathy/skepticism, boundary concerns, external locus of competence, utilize external resources, counselor approaches, and client movement/change.

\section{Apathy/Skepticism}

Of the 64 participants in this study, there were 26 (41\%) who shared an attitude of apathy or skepticism regarding the big claw activity. Some of the actual responses were the following: "I actually had bad thoughts before I started." "I didn't care what I got." "I had low expectations. I got what I expected." "I got nothing to show for my efforts. It was just a loss."

\section{Boundary Concerns}

The participants were instructed to take a maximum of five attempts and to engage in the big claw activity alone (not accompanied by an acquaintance). Via the participants' reports, the researcher discovered that the number of participants who chose to exhibit behaviors beyond the boundaries of the activity's instructions were significant enough to declare as an emergent theme. Of the 64 participants, 20 (31\%) were not compliant with the directive to take a maximum of five attempts at grabbing a prize. Some of the actual responses from participants who did not comply with the maximum attempt instruction were the following: "I gave up and stopped after my 3rd attempt." "I spent more money and took more attempts than specified." "I did an extra attempt beyond the 5 to try and get something." "I won 2 items and spent \$15." "I played until I ran out of coins." "I kept trying until I got something."

Of the 64 participants, 14 (22\%) mentioned they were accompanied by a loved one or acquaintance (despite the instructions to go alone). Some of the actual responses were the following: "My mom was present and sister and helped pick the machine." "I took my boyfriend. He wanted to do it, but I didn't let him. He just gave advice." "I took a friend with me because I was embarrassed." "My hubby and sister were in my ear, helping" "My husband came to help, but I did not need his pointers."

\section{External Locus of Competence}

Several participants voluntarily mentioned being conscious that there were onlookers within proximity of their chosen big claw machine. The author saw this phenomenon as a noteworthy trend. Of the 64 participants, 12(19\%) expressed an emphasized perception that outsiders were evaluating their competence.

Some of the actual responses were the following: "People stopped and looked at me." "I was embarrassed the whole time." "A lady came up with her kid and gave me the eye" "There were kids and parents around giggling at me" "I got so frustrated. I felt like 
an idiot, talking to the machine, asking it 'Why won't you do what I want!"”

\section{Discussion}

The results of this study provided the data necessary to tentatively answer the research questions. The author was able to identify several themes that allowed for a description of the behaviors and emotions the participants experienced during their big claw activity and follow up debriefing. From the collected transcribed data, process themes were ascertained from the participants' words. These general essence themes may offer some insight as to how the participants psychologically approach their work and how they viewed clients' movement toward personal growth.

\section{Counselor Approaches}

After the big claw activity, and during the debriefing session, several of the participants appeared to be able to conceptualize the metaphoric connection between the big claw activity and their ideas of self in relation to counseling. Through the big claw activity, the following participant seemed to recognize not only the incomplete feelings of not reaching a client's goals, but also the reality of premature terminations: "I had thought about clients, reaching down to help them, but can't pick them all up. Sometimes pick up part way, then drop them. They don't come back". The following statement was from a participant who appeared to become cognizant of his or her own need to be in control of the counseling process with the following statements: "My controlling nature has a difficult time with this. I will need to learn how to be flexible and try to see from the client's perspective." Another participant appeared to have a similar perception, as evidenced by the following statement: "I don't like to play a game and come away empty handed. This activity helped me see a side of myself that I will need to work on before becoming a professional counselor." Another participant appeared to gain a better understanding of the oftentimes futile efforts of the counselor's work, with the following statement: "I observed another lady after me, and she didn't get anything either. I think I learned that some client's issues would be difficult for even the best therapists to work with."

The following statements were from participants who appeared to view the work of a counselor as frustrating, particularly when one's best efforts are rendered fruitless: "There was a loose, easy one on top. I knew I could get that one." Another participant stated, "I kept trying to get the same toy, and was disappointed I could not get it." A third participant made the following observation, "I tried the same approach and landed in the same spot."

\section{Client Movement / Change}

Several of the participant's reactions exhibited the notion conceptualizing the metaphoric connection between the big claw activity and their ideas of client emotional movement or change. Following are a few selectstatements and content from the debriefing discussion with the participants within parentheses: "Moved a dog one inch." (as if small changes are oftentimes appropriate levels of client success). "I got 2 in one try." (sometimes when attempting to accomplish one counseling goal, other, connected client needs are also addressed). "Bunch of items. Looked like a bunch of parents cleaned up their kids' rooms and dumped into the machine." (when considering some clients who readily unload numerous issues in the initial session. "It appears they pack those machines." (oftentimes client concerns are layered, one atop the other). "I got a bear by the ear and got him almost to the hole." (taking into consideration client resistance, then sabotage when there is successful movement toward a counseling goal).

"Went for a bunny. Grabbed his ear, but his leg was wrapped around another toy." (there are moments when a 'surface' concern is attached to a deeper, more meaningful one). "Tried to get a smurf. It was so deep, but I thought I could get it because the head was so big." (there are times when clients display their most concerning issue early, but not enough rapport has been established to successfully access the depths of the concern. "I spent my 5 times and got a toy really loose. A kid was watching and stepped up right after I did and got my toy" (there are times when we work hard to help a client move some emotional 'stuff', but termination ensues prior to accomplishing goals. There can be satisfaction believing that the next therapist, or therapeutic moment might complete the work that we started.

\section{Conclusion and Implications}

Metaphors could transcend reality, reframe issues, and present more vivid imagery. The inspirational properties of metaphors have been extended into counseling courses. As ascertained from the review of related literature, as well as the current study, metaphors are widely accepted avenues for displaying the ingenious internal resources of counselors [26]. Metaphors have also been acknowledged as effective for facilitating transitions. The current study sought to explore how counseling students utilized metaphors to transition from the skills development phase of their training, to the actual practice of those skills with clients at their internship sites. The overall responses from graduate counseling students were positive. During the post activity discussion / processing session, several students commented on how the big claw metaphorical activity helped them see how they were initially approaching the novelty and challenges of their practicum experience. Some students commented on their fears, anxieties, and apathetic attitudes with regards to the big claw metaphorical activity.

Many of these same students mentioned that they tend to approach many novel tasks in a similar way. Other students mentioned an approach of overconfidence, ultra- competitiveness, and 'by any means necessary' to the activity, which many also confirmed they take a similar approach in most challenging tasks. Some participants stated that they learned to approach their counseling practicum experience with a healthy balance of confidence and humility. Other participants mentioned how the processing of the activity with their instructor and classmates helped to modify their perceptions of the actual counseling process. 
Counselor educators can use the big claw metaphorical activity, or a modification of it to ascertain certain pre-loaded perceptions their students may have with regards to their role as a counselor, as well as their idea of the counseling process. The big claw activity or a similar metaphorical task can be implemented at a different phase of the students' education, if the educator deems an earlier course as more appropriate.

Bandura's (1977) research indicated that individuals who possessed high levels of self- confidence in their own abilities would approach difficult tasks as challenges rather than as obstacles and approach threatening situations with assurance that they can exercise control over the situation. Although there were several participants in this study who shared feelings of paralyzing anxiety with regards to their abilities to assist their internship clients, most of the counseling interns who participated in this study expressed feelings of excitement, as if reframing their anxiety into an accomplishable challenge. In further support of this notion, Bandura (1997) later stated the level of counselor self-efficacy may suggest that other social cognitive constructs, such as counselor anxiety and outcome expectations, may be important facilitators in the relationship between counselor self-efficacy and counselor performance. In the current study, most of the participants were able to perceive their anxiety as a helpful aid in propelling them into a higher mode of performance.

\section{Acknowledgement}

None.

\section{Conflicts of Interest}

No conflicts of interest.

\section{References}

1. Sawyer C, Peters ML, Willis J (2013) Self-efficacy of beginning counselors to counsel clients in clients. The Journal of Counselor Preparation and Supervision 5: 30-42.

2. Al Darmaki FR (2004) Counselor training, anxiety, and counseling selfefficacy: Implications for training psychology students from the United Arab Emirates University. Social Behavior and Personality 32: 429-439.

3. Bandura A (1977) Self-efficacy: Toward a unifying theory of behavioral change. Psychological Review, 84: 191-215.

4. Bandura A (1986) Social foundations of thought and action: A social cognitive theory. Englewood Cliffs, Prentice-Hall, New Jersey, USA.

5. Bandura A (1994) Self-efficacy. In VS Ramachaudran (Ed), Encyclopedia of human behavior, NY: Academic Press, New York, USA, 4: 71-81.

6. Bandura A (1997) Self efficacy: The exercise of control. Freeman, New York, USA.

7. Larson LM, Daniels JA (1998) Review of the counseling self-efficacy literature. The Counseling Psychologist 26: 179-218.

8. Barnes K (2004) Applying self-efficacy theory to counselor training and supervision: A comparison of two approaches. Counselor Education and Supervision 44: 56-69.

9. Lambie GW, Vaccaro N (2011) Doctoral counselor education students' levels of research self-efficacy, perceptions of the research training environment, and interest in research. Counselor Education and Supervision 50: 243-258.

10. Bernard J, Goodyear R (2009) Fundamentals of clinical supervision (4 $4^{\text {th }}$ ed.) Upper Saddle River, Pearson Education, New Jersey, USA.
11. Lent RW, Hoffman MA, Hill CE, Treistman D, Mount M, et al. (2006) Client- specific counselor self-efficacy in novice counselors: Relation to perception of session quality. Journal of Counseling Psychology 53: 453463.

12. Mullen PR, Uwamahoro O, Blount AJ, Lambie GW (2015) Development of counseling students' self-efficacy during preparation and training. The Professional Counselor 5: 175-184.

13. Fernando DM, Hulse Kilacky D (2005) The relationship of supervisory styles to satisfaction with supervision and the perceived self-efficacy of Master's level couneling students. Counselor Education and Supervision 44: 293-304.

14. Dana HL, Jacques JD (2005) Promoting tolerance for ambiguity in counselor training programs. Journal of Humanistic Counseling, Education, and Development 44: 46-54.

15. Jennings L, Goh M, Skovholt TM, Hanson M, Banerjee Stevens D (2003) Multiple factors in the development of the expert counselor and therapist. Journal of Career Development 30: 59-72.

16. Levitt DH, Jacques JD (2005) Promoting tolerance for ambiguity in counselor training programs. Journal of Humanistic Counseling Education and Development 44: 46-54.

17. Kaufer D (1983) Metaphor and its ties to ambiguity and vagueness. Rhetoric Society Quarterly 13: 209-220.

18. Metaphor (2003) In Merriam-Webster's dictionary (11 $1^{\text {th }}$ edn), Springfield, Merriam-Webster, Massachusetts, USA.

19. Fox R (1989) What is meta for? Clinical Social Work Journal 17: 233-244

20. Powell A, Royce JR (1978) Paths to being, lifestyle, and individuality. Psychological Reports 42: 987-1005.

21. Inkson K (2002) Career metaphors and their application in theory and counseling practice. Journal of Employment Counseling 39: 98-108.

22. Lyddon WJ, Clay AL, Sparks CL (2001) Metaphor and change in counseling. Journal of Counseling and Development 79: 269-274.

23. Wickman SA, Daniels MH, White LJ, Fesmire SA (1999) A primer in conceptual metaphor for counselors. Journal of Counseling and Development 77: 389-394.

24. Johnson M (1993) Conceptual metaphor and embodied structures of meaning: A reply to Kennedy and Vervaeke. Philosophical Psychology 6: 413-422.

25. Hoskins M, Leseho J (1996) Changing metaphors of the self: Implications for counseling. Journal of Counseling and Development 74: 243-252.

26. Robert T, Kelly VA (2010) Metaphor as an instrument for orchestrating change in counselor training and the counseling process. Journal of Counseling and Development 88: 182-188.

27. Leary DE (1990) Metaphors in the History of psychology. Cambridge University Press, New York, USA.

28. Langer SD (1948) Philosophy in a new key: A study of the symbolism of reason, rite, and art. Brunner/Mazel, New York, USA.

29. Tang M, Addison KD, LaSure Bryant D, Norman R, O Connell W, et al. (2004) Factors that influence self-efficacy of counseling students: An exploratory study. Counselor Education and Supervision 44: 70-80.

30. Pearson QM (2003) Polished rocks: A culminating guided imagery for counselor interns. Journal of Humanistic Counseling, Education and Development 42: 116-120.

31. Sommer C, Cox JA (2003) Using Greek mythology as a metaphor to enhance supervision. Counselor Education and Supervision 42: 326335.

32. Campbell J (1988) The power of myth. Doubleday, New York, USA.

33. Guiffrida DA, Jordan R, Saiz S, Barnes KL (2007) The use of metaphor in clinical supervision. Journal of Counseling and Development 85: 393400.

34. Giorgi A (1985) Phenomenology and psychological research. Duquesne University Press, Pittsburgh, USA. 
35. Polkinghorne DE (1989) Phenomenological research methods. In RS Valle, S Halling (Eds.), Existential-phenomenological perspectives in psychology, Plenum Press, New York, USA, pp. 41-60.
36. Lincoln YS, Guba EA (1985) Naturalistic inquiry. Sage, Beverly Hills, California, USA. 